\title{
Improving ITAL's Peer Review
}

Kenneth J. Varnum

Over the past several months, ITAL has enrolled almost 30 reviewers to the journal's new review panel. Increasing the pool of reviewers for the journal supports the Editorial Board's desire to provide equitable treatment to submitted articles by having two independent reviews provide double-blind consideration of each article, a practice that has now been in effect for articles submitted after May 1, 2021. I am grateful to the individuals (listed on the Editorial Team page) who volunteered, attended an orientation session, and have begun contributing to the work of the journal.

\section{IN THIS ISSUE}

In the editorial section of this issue, we have a column by incoming Core president Margaret Heller. Her essay, "Making Room for Change through Rest," highlights the need for each of us to recharge after a collectively challenging year. This inaugurates what we plan to be an occasional feature, the "Core Leadership Column," to which we invite contributions from members of Core leadership. It is joined by two other regular items, our Editorial Board Thoughts essay by Michael P. Sauers, "Do Space's Virtual Interview Lab: Using Simple Technology to Serve the Public in a Time of Crisis" and William Yarbrough's Public Libraries Leading the Way column, "Service Barometers: Using Lending Kiosks to Locate Patrons."

An interesting and diverse set of peer-reviewed articles round out the issue:

1. The Impact of COVID-19 on the Use of Academic Library Resources / Ruth Sara Connell, Lisa C. Wallis, and David Comeaux

2. Emergency Remote Library Instruction and Tech Tools: A Matter of Equity During a Pandemic / Kathia Ibacache, Amanda Rybin, and Eric Vance

3. Off-campus Access to Licensed Online Resources through Shibboleth / Francis Jayakanth, Anand T. Byrappa, and Raja Visvanathan

4. A Framework for Measuring Relevancy in Discovery Environments / Blake L. Galbreath, Alex Merrill, and Corey M. Johnson

5. Beyond VIAF: Wikidata as a Complementary Tool for Authority Control in Libraries / Carlo Bianchini, Stefano Bargioni, and Camillo Carlo Pellizzari di San Girolamo

6. Algorithmic Literacy and the Role for Libraries / Michael Ridley and Danica Pawlick-Potts

7. Persistent URLs and Citations Offered for Digital Objects by Digital Libraries / Nicholas Homenda

Kenneth J. Varnum, Editor

varnum@umich.edu

June 2021 